\title{
INFORMATION FOR ALL: RESOURCE GENERATION AND INFORMATION REPACKAGING IN NIGERIAN SCHOOLS
}

\author{
Virginia Dike \\ Senior Lecturer \& Head \\ Department of Library Science \\ University of Nigeria \\ Nsukka, Nigeria \\ Nancy O. Amucheazi \\ Head of Technical Services \\ University of Nigeria Library \\ Nsukka, Nigeria
}

\begin{abstract}
Is a developing country like Nigeria information rich or information poor? The first impression is of scarcity, but a closer examination reveals unexplored riches. There is a wealth of information in the oral tradition, but it is not found in schools and libraries. There is information in libraries, but language and reading level make it inaccessible to school children. What role might libraries play in resolving the information dilemma in Nigerian primary schools? This paper explores the use of resource generation from oral tradition, and information repackaging from oral and written sources, in creating an information and knowledge rich environment for all children.
\end{abstract}

\section{INTRODUCTION}

Is a developing country like Nigeria information rich or information poor? Certainly the first impression is of poverty. The information superhighway as exemplified by the Internet and e-mail is only beginning to enter high level institutions in major centers. Even at the universities, most work is done without the aid of computers. Turning to more traditional information sources, the terms "book hunger," "book famine," and "bookless societies" have been used to characterize Africa in recent years. Indigenous publishing, just trying to find its feet, has been badly hit by the deteriorating economy, while the thin stream of foreign books has almost dried up. Libraries are few and far between. Turning to the schools, especially the primary schools which are the focus of this study, one finds an almost total lack of teaching/learning materials. The situation is such that Sturges and Chimseu (1996) suggest we talk, not of "book famine," but of "information famine," for there are problems with obtaining information in any form, be it print, electronic, audiovisual or oral. Nigeria would certainly appear to be information poor.

And yet, there is perhaps another side to the picture. Could Nigeria in any way be information rich? It has been argued that many development policies for Africa have failed, not because of a lack of information brought in from outside, but because of the failure to make use of information from inside. There has, according to Sturges, Mchombu and Neill (192) been an "almost willful disregard of the information resources available in the continent." (p. 12) These neglected resources include oral indigenous information concerning the natural and social environment, occupations and cultural arts, societal norms and values, as well as varied forms of oral literature. The indigenous knowledge base also includes locally-produced print materials in many forms: books and periodicals, but especially the neglected resources of gray literature-technical reports, conference papers, pamphlets, flyers, etc. Perhaps there are ways we can capture and utilize this indigenous knowledge base, for development-and for education. 


\section{INFORMATION FOR ALL}

According to Article 9 of the Universal Declaration of Human Rights, "everyone has the right...to seek, receive and impart information and ideas through any media." Several authors (Sturges, Mchombu \& Neill, 1992; Totemeyer, 1994; Rachnema, 1982) have stressed the need to expand our vision if we are to provide information for all. For "any media" include print, electronic and audiovisual media - and the human voice which is still the cheapest and most natural mode of communication (Totemeyer, 1994). too often we assume a linear progression from oral to print to electronic media, or we regard literacy as a prerequisite for the communication of information. Rahnema (1982) suggests we shift emphasis from "reading the word" (i.e., literacy and written media) to "reading the world," making use of any appropriate medium in our quest for understanding.

For Africa these appropriate media are often likely to involve oral communication. Chakava (1984) and Ogunsheye (1976), among others, have noted that most Africans derive more pleasure from oral and performing arts-talking, singing, dancing, and dramatizing - than from the rather private and solitary activity of reading. African culture, with its emphasis on the oral mode and communal nature of learning has attuned people to learning more through the "ear" than through the "eye". Totenmeyer (1994) gives the example of Namibian university students, who are more apt to internalize an important lecture by reconstructing and discussing it as a group than by taking notes or recording it on tape. In addition to this cultural affinity, a large proportion of the population in Nigeria and many African countries has not acquired literacy and is thereby cut off from information in written forms. The multiplicity of languages, underdeveloped infrastructure and poverty, all complicate the provision of print and electronic media for meeting people's information needs. By exploring appropriate oral means of information transfer, whether through direct communication or audio technology, along side all other possible media, we can both extend the information available to us and make information more accessible to all.

\section{RESOURCE GENERATION}

While the value of the indigenous knowledge base may be acknowledged, capturing and repackaging it in appropriate forms for use is a major challenge. First, it must be recognized that some loss results when information is removed from its elastic "human envelope" and put in more durable static forms. Yet this process of information capture fosters its preservation and enables it to be used more widely.

Early projects of resource generation from oral information sources focused on rural adult learners, who are cut off from information in traditional library resources due to lack of literacy. As early as 1972, Oyeoku (1975) opined that: "The initial emphasis of African libraries need not be on the printed word. It is quite feasible and more meaningful to start a library in a rural community with miles of tapes of the people's folklore, music and culture." (p. 280)

Oyeoku proposed a program for generating resources in stages, whereby librarians would collect oral materials from the people to create a community library of tapes. These could also be transcribed to provide familiar and appealing reading materials for new literates. He also envisioned using this sound library to prepare learning materials for primary school children. Operation Lecture Publique of Mali (Rahnema, 1982; Mali, 1992) implemented this idea with a system of sound libraries recording and making Mali's oral tradition available throughout the country.

A small-scale local example of information capture is provided by the second presenter's oral information project with graduate students of library science. The students generated information from interviews with rural people on subjects such as making of black soap, treatment for measles, weaving of akwete cloth and preparation of local food condiments. The information so generated was both recorded on audio cassette and transcribed in written form. Specimens and photographs of the important elements were also included, creating multimedia resources for an oral archive. Such resources might also be adapted for classroom teaching in primary school subjects such as social studies, science, and home economics. 


\section{INFORMATION REPACKAGING}

Information resources may not be accessible to users in their original form for a number of reasons, chief among these being illiteracy of users, the language of presentation, reading level, or differences in intended audience. In these cases, information must be "repackaged" to suit the particular users. Information repackaging involves extracting relevant information from a variety of sources, simplifying or translating materials into the language of the target population, and presenting information in oral, visual, or a combination of media.

Aboyade (1984) used this concept in her RUDIS project, in which a research team from the University of Ibadan extended information services to the villagers of Badeku. While the team took some information materials with them, they also responded to the needs expressed by the people. Repackaging took the form of giving oral information on agriculture, health and government policies, but also of reading stories or football match reports to the villagers.

Surges and Chimseu (1996) considered the potential of gray literature as content source material for repackaged development messages in Malawi. They described several small projects of the public library service and relevant government ministries in which information culled from technical reports, conference papers and government documents was put in simplified summary form for extension workers to communicate to rural dwellers using the local language. Oral messages were supported by a wide variety of written and audiovisual materials produced by the project, such as booklets, posters, puppet shows, and t-shirts.

Our focus in this paper is to explore whether these approaches for providing information to adults might also be utilized with school children. Having looked at previous work, we now turn to the setting for our project.

\section{THE NIGERIAN EDUCATIONAL SETTING}

Indigenous Nigerian education was carried out by members of the family and community, using predominantly informal methods reminiscent of modern educational philosophy and practice. The variety of methods used include oral presentation through telling stories, recounting history, posing riddles; guided observation and instruction in the context of daily life; demonstration and hands-on experience as in apprenticeship. Education was thoroughly grounded in the culture and aimed at developing fully productive citizens to meet varied societal needs. The modern school system, however, did not evolve from this base. Western-type education was introduced by Christian missionaries in the late 19th and early 20th century. Most schools were run by missions, receiving some support and regulation from the British colonial government. The aims of this new education were different, seeking to draw children away from aspects of their culture and into a new sociocultural system. Education expanded rapidly, especially after independence and through the 1960's and 1970's. In the early 1970's the government took over the schools, providing a public school system throughout the country. The 1980's brought a downturn in the economy which has worsened in the 1990's. The worsening economy has adversely affected the ability of parents to send children to school and equip them with basic materials and textbooks. Hard times have also affected the availability of resources for learning, as library services, the publishing industry and book trade have declined. Hard times in combination with politics have lowered the morale and quality of teachers, the basic human resource of education. Education in Nigeria is in disarray.

\section{EDUCATIONAL POLICY}

Nigerian education at all levels is guided by the National policy on education (Nigeria, 1981). This document articulates a philosophy and structure felt to be more in keeping with national aspirations and needs in the modern world. Several provisions of this policy are of special relevance to this study. 


\section{Learner-centered and Resourced-based Education}

The Policy stresses the need for learner-centered, self-directed and lifelong education. Pursuant to this it comes out strongly in favor of modern methods and against the former pattern of memorization and regurgitation of facts. This is especially pronounced at the primary school level, where "practical, exploratory and experimental methods" (Section 3, sub-section 3) are encouraged in order to develop "the ability to communicate effectively, scientific and reflective thinking, and the ability to adapt to a changing environment." (Section 3, sub-section 14) The Policy also stresses the need for learning resources and school libraries to support these objectives. But while the Policy emphasizes resource-based learning and learner-centered education and recognizes the place of the school library in making this feasible, not much has been done in actual situations to translate these aims into reality.

\section{Language of Instruction}

English, not the Nigerian languages, has been the predominant language of education. Having to learn in a second language puts children, especially younger children with no prior knowledge of the spoken language, at a serious disadvantage. Recognizing this problem, the Policy states that nursery school and the first three grades of primary school shall be conducted in the mother tongue. The aim is to gradually shift to English in grades 4 to 6 . This policy has been both controversial and problematic in ways which cannot be pursued here. The fact that Nigeria has a multiplicity of languages (410 according to a BBC broadcast of April 19, 1997), many of which have not been transcribed, and that there are only a handful of primary school books even in three major languages indicates the scope of the problem. There are virtually no learning resources presently in use to support education in the mother tongue, yet this is the language spoken and understood by school children. The result is that, in a homogeneous community such as that of our study, lessons are explained to the children in Igbo throughout primary school, but the syllabus, textbooks, notes written on the board, and the examinations are all in English.

\section{Teaching of Reading}

The attainment of permanent literacy and numeracy is the first of the objectives of primary education. Yet many young people finish primary school or even secondary school without attaining basic literacy in either the mother tongue or in English. Among the obstacles children face in learning to read are their oral background, the illiteracy of parents, the current harsh economic conditions, and the use of a second language. It has also been mentioned in these studies that the entire education system presents obstacles to literacy and there is highly limited access to books and other reading materials (Dike, 1994; Emejulu, 1990).

Examination of the curriculum reveals that reading is not taught as a separate subject but is one of the four activities in the teaching of English language. Moreover, one cannot pinpoint any method of teaching reading beyond copying and repeating sentences the teacher writes on the board. There is no reference to phonics, not even learning the sounds of the letters. Studies of reading confirm the lack of instruction in methods of teaching reading in the teacher training curriculum (Emenyonu, 1993). In the early years learning to read is complicated by the fact that children are being introduced to a new language along with reading. As a result there is no oral foundation on which to build. The problem of reading is also intertwined with the problem of second language instruction. The instructors are not native speakers and do not have full mastery of English. Learning to read in both English and the mother tongue is hindered by the lack of reading materials at beginning levels-hardly existent in Igbo, often inaccessible or culturally unfamiliar for English. yet inability to read cuts children off from much of the information they require for fuller understanding of the world.

\section{The Curriculum}

In order to further implement the National Policy on Education, the National Implementation Committee oversaw preparation of Primary School Curriculum Modules for grades 1 to 6 (Nigeria, 1989). The curriculum modules are intended to assist teachers by outlining content and suggesting methods, activities and resources appropriate for the various lessons. The modules explicitly direct teachers to other resources for information to fill in the outline. Most teachers, however, lack access to other resources beyond, perhaps, a textbook. Pupils are also limited to the textbook, if one is available 
to them: they lack reference tools, topic books, fiction, audiovisual materials, in short, the learning resources which make up a library collection

One might note two additional features of the curriculum. First, it is based on foreign primary curricula gradually adapted for Nigeria. It did not evolve from the traditional education of Nigerian societies. While content has been Nigerianized, it may be that some aspects or emphases of indigenous education are not adequately reflected due to this pattern of development. Second, both the curriculum and the textbooks derived from it attempt to homogenize Nigerian culture to produce something suitable for the whole country. This attempt to find the lowest common denominator for what is a very heterogeneous society results in a bland and sketchy picture. Resources deriving from the local community might provide the meat to flesh out the skeleton, giving the specifics and vivid detail which lend interest. Their use would also enable children to base learning in their own experience and apply what is learned to the local situation.

\section{PROJECT IN A PRIMARY SCHOOL}

The researcher sought ways of improving primary school education by applying the ideas gained from previous work with adult learners. The aims were to develop resources from information available within the community, repackage information not accessible to children in its current form, and help children learn how to find and utilize information from a variety of sources.

\section{The Setting}

The setting for the project is a rural primary school in Nguru, a village near the university town of Nsukka. Like many primary schools, classes are conducted in long halls with clusters of desks arranged before sections of the wall painted to create blackboards. The pupils' desks are made to carry to school. As a result, the work surface may be as narrow as 5" x 20". This introduced unanticipated difficulties in carrying out learning activities, as there was no space to spread work out or support papers while drawing. The light provided by open windows high in the wall is inadequate; classrooms are often dark on overcast days. Moreover, there is no electrical power in the school. All of these factors present obstacles to learning.

We selected a rural school on the grounds that it would have a homogeneous population and be a more integral part of the local community. As a result, oral indigenous knowledge might be more readily available to pupils than in an urban setting, where the pupils' families have left their communities of origin. Moreover, urban schools on the whole might have slightly better facilities and more access to library and other resources.

One junior class, Primary 2, and one senior class, Primary 5, were selected for the project. Activities were planned by the two presenters and carried out with assistance from the class teachers. The Igbo speaker (Amucheazi) worked with the junior class and the non-Igbo speaker (Dike) with the senior class. Language, not surprisingly, was a limitation, especially for the non-Igbo speaker, but also to some extent for the Igbo speaker, who is from another area and therefore speaks a different dialect. It would have been desirable to make use of library science students as resource persons, as had been done in the past, but the university was no in session during the period.

\section{Procedure}

We began by looking at the pupils' entry behavior. What did they already know? What did they bring to the learning situation? We identified several elements, among them the spoken language, previous life experience and oral literature.

The spoken language. The children have a good command of spoken language in their mother tongue. They and their teachers share a common language, Igbo, and in most cases, the same dialect, Nsukka. Whatever difficulties children may encounter with written language, their command of oral communication makes the mother tongue an effective medium for instruction.

Previous life experience. School children have built up a knowledge base from the home environment. They are familiar with the objects and routines of everyday life, aspects of the natural environment, family relationships, social norms and structures, and common life experiences, such as the birth of a younger sibling, having a pet, taking a vacation to visit relatives (many of which are characteristic of human experience everywhere). 
Oral literature. The oral tradition of storytelling and folklore remains fairly strong, in spite of some erosion. Several studies have revealed that most parents still tell stories to their children (Emejulu, 1990; James, 1981). Other folklore-songs, riddles, games-are learned from other children or adults in the community. From church attendance and religious education, children also are familiar with Bible stories. This body of literature constitutes a valuable resource for learning.

\section{Information Sources within the Community}

We next identified possible sources of information which might be made available for teaching and learning and ways these might be used in developing information skills.

Community sources. In addition to what children already know, there is a wealth of information within the local village community. Oral indigenous information concerning occupations, social institutions, cultural arts, plants and animals, domestic science, agriculture and health might be collected and repackaged as required to create resources for learning. Possible resource persons include parents and other family members, elders, and a variety of experts, both traditional and modern. The community also holds material resources such as realia, natural sites, and institutions.

Library resources. The most ready source of appropriate library resources is the Children's Centre Library at the nearby University of Nigeria. Through projects such as this one, its books, periodicals and audiovisual materials can be made accessible to schools. While almost all the materials are in English, and most at too high a reading level for public school children, this collection contains a wealth of information suitable for repackaging to meet the needs of the target audience. Likely approaches include oral mediation by teachers using the mother tongue, simplifying or translating text of information books and magazines, and creating audiovisual resources such as charts and albums. An additional source from within the university is projects from courses on oral information, audiovisual librarianship, and library work with children.

Development of information skill. We also considered how school children might utilize community information sources in learning how to find out. The Nambia syllabus for basic information science (1991) utilizes this approach by beginning with the most familiar and accessible information sources. By consulting human sources such as teachers, community leaders, elderly people and experts, children develop interviewing, listening, and questioning skills. Environmental sources such as nature, village and town/city help develop skills in observation, description, and interpretation. Use of human and environmental sources is especially important for information education at primary school level since the pupils' level of literacy precludes the use of many written sources of information.

\section{Learning Activities}

These ideas were tried out with learning activities in four areas: cultural arts, science, social studies, and language.

Storytelling-cultural arts (primary 2). The Igbo have a rich tradition of folklore for children which they use as a means of enculturation and socialization. This folklore can be song-based, storybased, speech-based, or activity-based. Traditionally stories were among the chief means of molding the character of the Igbo child. They also served as a repository of knowledge about the environment. Today they might also serve as a way of reasserting pride in traditional values and culture, which has been eroded by colonialization and modernization.

Yet it has been observed that the schools play little role in transmitting this cultural heritage (Emejulu, 1990). Children hear stories from their parents, relations and playmates, not from their teachers. If stories are told at all in the school setting, it is likely to be as a time-filler at the end of term. This reflects the teachers' view of folk tales as a form of amusement, rather than a valuable resource for learning.

Activities in the junior class began with reading aloud simple picture books in English as an aid to English language instruction. But most children could not follow even the simplest stories unless they were translated into Igbo. Children were, however, eager to tell many stories in their 
unless they were translated into Igbo. Children were, however, eager to tell many stories in their Nsukka Igbo dialect and sing some simple folk songs. Most of their stories were on animals like the squirrel, the $\operatorname{dog}$ and the monkey. Similar stories were translated and read aloud in their mother tongue. They also named animals they know as part of a singing game and talked about their habits. Their stories and rhymes were taped and repackaged into class-made story books. The activity showed that these forms of oral literature are ready to be tapped as a major resource for enriching the learning environment.

Social services and institutions-social studies (primary 5). Social studies is the primary school subject perhaps most in need of locally generated resources for effective teaching because of the diverse Nigerian cultural environment. Yet the textbooks try to present a generalized Nigerian culture that does not adequately reflect reality or provide adequate detail. Elaturoti (1986) made this same point with regards to the Abadina project using local resource persons to generate learning resources for social studies. A collection of taped interviews was developed on topics like festivals, foods, the family, government, and folklore, using a wide variety of resource persons from the local community.

Observing the same need, we organized learning activities whereby the children themselves would gather information through interview and present their findings orally in class. Using topics relating to the primary 5 syllabus, pupils interviewed members of the community connected with local and traditional government, banks, markets, the motor park, postal and telephone services, the water board, and other similar institutions. When possible, students visited the locations. Pupils also gathered information on festivals, preparing albums on masquerades, seasonal celebrations, marriage and naming ceremonies. These resources are useful both in being tailored to the immediate environment and offering a means of expanding knowledge through exchange with other communities. The activity enriched knowledge and helped develop interview, observation, and presentation skills.

Animals around us-science (primary 2 and 5). Taiwo (1980) has emphasized the importance of the natural environment in traditional Nigerian education. Yet the primary science curriculum touches lightly on the specifics of the world around-its animals, plants, physical features, geology, seasons, and habitats. A previous project related to African wildlife, using information obtained from books and magazines in the Children's Centre Library. Children in primary 4 - 6 were able to write and illustrate a big book on African animals as a group project. However, it was found that even books in beginning English had to be read aloud and explained in English or Igbo. Or, one child in a group of six could attempt the work while the others were reduced to onlookers. These observations led to the new approach for the initial stages, generating resources based on direct experience and repackaging information from written sources to suit the target audience.

The first step was compiling a list of animals the children knew. Children in primary 2 named many domestic animals in their environment and talked about their habits. Primary 5 pupils were asked to write what they knew about the animal and draw a picture. It was found that written expression was very limited in both Igbo and English and that children had very limited knowledge of animals outside their home environment.

The next step was to identify information which could be repackaged for use by the children. This was located in books, magazines and encyclopedias from the library. Other sources of information included locally produced materials such as an album on hunting made by a graduate student of audiovisual librarianship from oral sources. Expanded text on the various animals was written to supplement the information provided by the children. Other information was translated and communicated orally by the teachers. With this expanded information the class created a book with Igbo and English text. Traditional stories about the animals were added, creating a book which combined information and folklore.

A second activity involved creating resources from observation of birds. Initial sources included observation notebooks, West African field guides, and pictures. After an introduction, children were asked to record their observations of birds in the community. A format was designed to guide their observations of appearance, habitat, behavior, etc. Charts of colors, sizes and parts of the body were made to assist with vocabulary. Thus, the project aimed at expanding pupils' knowledge and appreciation of the natural world, increasing their observation skills as a tool for gaining information, and improving their mastery of English language. 
Creation of reading materials-language (primary 2). The problem of language has already been noted above. While utilizing oral communication in the mother tongue, children also need to master English if they are to have access to the wider world of knowledge. One problem is finding reading materials with simple language and familiar content. Often such materials can be provided only through local generation of resources, even in some instances by the children themselves.

The importance of familiar content for beginning readers is a widely accepted concept. Studies carried out in the Laboratory for Children's Librarianship at the University of Haifa Library in Israel (Server, 1994) revealed that beginning readers have a marked preference for familiar stories and books and therefore could be helped by picture books read aloud and stories being told to them. This would build up their repertoire of stories and story patterns for reading. Studies in Nigeria (Emenyonu, 1993) have confirmed children's preference for familiar stories.

Yet books for younger children have the fewest titles in local publishing. The readers who most need familiar content and background are the most deprived. To help make up for this deficiency, common to most developing countries, pupils and teachers have created their own reading materials. In some South Pacific countries (Rainey, 1994), teachers and their primary school pupils have been able to 'publish' big books from stories and/or poems written by the pupils, corrected by their teachers, typed and bound into a collection of stories or poems. The Read project of South Africa (1994) has also used big books, created by classes to generate reading materials based on the local environment, using both the mother tongue and English.

Our project also used oral information provided by the children to produce materials for learning English. Children told a number of folk tales in class, which were recorded on tape. These were then illustrated and retold in simple English. In this way, familiar and appealing materials from oral tradition and the local environment provided a means of enhancing the children's reading ability.

\section{CONCLUSIONS}

While much remains to be done, much was learned from this preliminary project. Among the salient points from our experience are the following.

\section{Nigeria has a Wealth of Oral Indigenous Information}

There is a wealth of indigenous information in the rural Igbo community. It is communicated orally by experienced and mature adults to members of their group, including children. However, given the ephemeral nature of oral information and the many changes taking place within society, some aspects of this information may get lost unless ways are found to capture and preserve it. When this is done, the information may be disseminated to a wider audience beyond the community rather than being limited to direct person-to-person contact.

\section{Nigerian Children Face Many Obstacles to Learning}

Since the modern school system did not evolve from the traditional educations system, oral indigenous knowledge has not been effectively utilized in the school curriculum so that school children can benefit from such knowledge. Children are thus deprived of the wealth of information from their cultural background. They also have difficulty comprehending what is being taught and relating it to their lives.

Another obstacle to learning is an almost complete lack of learning resources. Even in the rare cases where books and other learning resources are available, almost all are in English, a second language, rather than in the mother tongue.

A third problem which makes learning difficult is that the children are barely literate in either English or their mother tongue. Therefore, if they are to learn, most of the information must be communicated orally in their mother tongue and, if possible, their dialect. This enables them to learn and the knowledge gained motivates and facilitates the learning of reading, which is a necessary step for further learning. 


\section{Information Repackaging is One Way of Overcoming These Obstacles}

In order to teach children through oral transfer of information, information must be repackaged from written sources. The teachers should be chiefly responsible for this oral transfer of information. There is also need to repackage information into written forms through simplifying or translating. Since it is unlikely that classroom teachers will have the opportunity or skills for this, repackaging from written sources requires cooperation of personnel in library schools, teacher resource centers, model children's libraries, or a unit specially set up for that purpose. We are seeking ways of setting up such a unit at the University of Nigeria.

\section{Adequate Information Cannot Be Found within the School}

While we began by seeking oral information from the children, they have serious limitations as to the scope and depth of their knowledge. It is therefore necessary to go beyond the school to reach those who have such knowledge. One approach is to send the children out to collect information from their parents, grandparents, older siblings, relations, and experts or authority figures on the history, customs, or occupations of the community. With such information children might generate learning resources in school. Students of library science can also help capture information as projects in relevant courses.

\section{Children Can Begin Developing Information Skills Without Literacy}

Children's lack of literacy makes it difficult to develop information by other means, such as observing their community and environment, and interviewing knowledgeable members of the community. A wide range of information skills can be gained through these learning activities.

\section{Information Repackaging Can Be Used to Promote Reading}

Although children can learn and develop information skills up to a point without literacy, they can have access to much more information if they can read, especially if they can read English. It is therefore important to find ways of creating resources for learning to read. One sure source is the repackaged oral indigenous information as found in stories, local histories and environment knowledge, with which children are familiar and which they also find appealing.

The most important message of this paper is that in a country like Nigeria where children labor to learn, partly because of a serious lack of learning materials, it is still possible to improve their learning potential in a number of ways. One of the surest and least expensive ways is by making maximum use of available information in the immediate environment, capturing and repackaging orally generated information into both sound and print form for use in the classroom. The idea of repackaging information is no longer novel since it has been used successfully with adult audiences in rural development. In this case, it is being tried as a means of helping children learn. It is hoped that in the face of several crippling disadvantages faced by Nigerian and other Third World school children, the librarians, classroom teachers, and educational authorities will team together to tap the best of the information rich local environment. They can do this by capturing and repackaging information to produce indigenous resources for the better education of children and provision of information for all.

\section{REFERENCES}

Aboyade, B. O. (1984). Communications potentials for the library for non-literates: An experiment in providing information services in a rural setting. Libri 34, 243-262.

Chakava, H. (19840 Reading in Africa: Some obstacles. IFLA Journal 19(4), 384-356.

Dike, V. W. (1994). Literacy without libraries: Promoting literacy among school children in Nigeria. In Literacy: Traditional, cultural, technological. Selected papers from the 23rd annual conference IASL, Pittsburgh, PA (pp. 33-41). Kalamazoo, MI: IASL.

Elaturoti, D. F. (1986). Use of resource people in generating resources for learning in Nigerian schools: Abadina Media Resource Centre, Ibadan, Nigeria. IASL Annual Conference Proceedings, 169-174. 
Emejulu, O. A. (1990). Traditional and modern media in the literary socialization of selected Nigerian children. Unpublished doctoral dissertation, University of Ibadan, Nigeria.

Emenyonu, P. T. (1993). Reading and the Nigerian cultural background. Enugu: New Generation.

James, S. L. (1981). Language habits and the early introduction to literature. In S. O. Unoh, (Ed.), Junior literature in English (pp. 137-148). Ibadan: African Universities Press \& Nigeria English Studies Association.

Mali. Ministry of Sports, Culture \& the Promotion of Youth. (1992). Operation Lecture Publique du Mali [Flyer]. Mali: Ministry of Sports, Culture \& the Promotion of Youth.

Namibia. Ministry of Education, Culture, Youth \& Sport (1991). Syllabus (junior secondary phase): basic information science, grades $8 \& 9$ [Mimeograph]. Namibia: Mistry of Education, Culture, Youth \& Sport.

Nigeria. (1981). National policy on education. Lagos: Ministry of Information

Nigeria. National Primary Education Commission. (1989). Primary school curriculum modules. Lagos: Evans.

Ogunsheye, F. A. (1976). Reading for development in urban Africa: The case of Ibadan. In F. E. Mohrhardt (Ed.), Reading in a changing world, Papers presented at the 38th session of the IFLA general council, Budapest, 1972. Munchen: Verlag Documentation.

Oyeoku, K. K. (1973). Publishing in Africa: Breaking the development barrier. In E. Oluwasanmi, et al. (Eds.), Publishing in Africa in the seventies (pp. 277-288). Ife: University of Ife Press.

Rahnema, M. (1982). The sound of library, a simple but revolutionary tool for development. Unesco Journal of Information Science, Librarianship and Archives Administration, 4, 156-157.

Rainey, M. (1994). Publishing children's books in a developing country. IASL Newsletter, 23(1), 1-2.

READ Educational Trust (1994). Annual Report. Braamfonteing, South Africa: Read.

Sever, I. (1994) Promoting reading among immigrants from an oral culture: Ethiopian Jews in Israel. Third World Libraries, 5(1), 17-23.

Sturges, P. \& Chimseu, G. (1996). Information repackaging in Malawi. African Journal of Library Archival \&Information Science, 6(2), 85-93.

Sturges, P., Mchombu, K. \& Neill, R. (1992). The indigenous knowledge base in African development. Journal of Economic \& Social Intelligence, 2(1), 5-29.

Totemeyer, A. (1994). Speaking from the book: The transfer of de-recorded information to the information starved. IFLA Journal, 20(4), 400-418. 